(C) The Author(s), 2019. Published by Cambridge University Press on behalf of The Hegel Society of Great Britain. This is an Open Access article, distributed under the terms of the Creative Commons Attribution-NonCommercial-NoDerivatives licence (http://creative commons.org/licenses/by-nc-nd/4.0/), which permits non-commercial re-use, distribution, and reproduction in any medium, provided the original work is unaltered and is properly cited. The written permission of Cambridge University Press must be obtained for commercial re-use or in order to create a derivative work.

\title{
Life and Mind: Varieties of Neo-Aristotelianism: Naive, Sophisticated, Hegelian
}

\author{
Andrea Kern
}

\begin{abstract}
In his treatment of subjective mind, Hegel argues that the development that characterizes the vital process of a human individual is logically unique in that it dissolves the contradiction between two logical determinations that characterize any vital activity: the contradiction between the 'immediate singularity' of the subject of this process and its 'abstract generality'. Hegel employs the term Bildung to characterize any vital activity that has this form. The idea that the distinction between human life and non-human life is a logical distinction is one of the main lessons that Hegel thinks we should learn from Aristotle's treatment of the idea of life. In this article I distinguish between two contemporary varieties of this Aristotelian idea: a sophisticated variety that emphasizes the idea of second nature in order to characterize the distinctiveness of the human, and a naive variety that thinks of the human's uniqueness in terms of characterizations that already belong to its first nature. I argue that Hegel is neither sophisticated nor naive but offers a third variety of Neo-Aristotelianism that solves the difficulties of the other two. This has decisive consequences for his understanding of Bildung. Although the notion of Bildung describes an empirical process, Hegel argues, it is not an empirical concept. Rather, it is the concrete concept of the process of actualization that characterizes a self-conscious form of life that reflects the inner temporality of this form's actuality.
\end{abstract}

I.

In his treatment of subjective mind, Hegel argues that the development that characterizes the vital process of a human individual is of a formally distinctive kind. It is a process that dissolves the contradiction between two logical determinations that characterize any vital activity. The vital activities of a human being, Hegel tells us, consist in a logical process of overcoming the contradiction of 


\section{Life and Mind}

the 'immediate singularity' of the subject of this process and its 'abstract generality' (\$396Z, 55/75). ${ }^{1}$ Hegel employs the term Bildung to characterize a vital activity that has this form. It is human life and only human life whose activity has this form.

The idea that the distinction between human life and non-human life is a logical distinction - that it is a distinction that does not consist in the content of the predicates applied to the individual, but in the form of their application to itis one of the main lessons that Hegel thinks we should learn from Aristotle's treatment of what he calls the 'form of life' as he expounds it in De Anima. In recent philosophy this broadly Aristotelian idea, according to which the distinctive character of human life consists among other things in human life containing a distinctive form of development, has been taken up and defended by authors who stress that the distinctiveness of human life is largely a matter of a human being's second nature. Its most prominent version is that of John McDowell, who argues that the characteristics which set human beings apart from any other non-human animal have to be conceived in terms of a process of Bildung (McDowell 1996: 123-26).

Paradoxically, however, the Aristotelian conception of a form of life has also been used and defended by authors who want to argue for the contrary position. These authors argue that the distinctive character of the human species can only be understood if we equip ourselves with a notion of human nature according to which its distinctive character is already part of its first nature. Its most prominent versions are the positions of G. E. M. Anscombe, Philippa Foot and Michael Thompson. Using a form of speaking suggested by Michael Thompson, I will call the former position 'Sophisticated Aristotelianism' and the latter position 'Naive Aristotelianism' (Thompson 2013).

In what follows I will argue that Hegel's account of the distinctiveness of human life is neither naive nor sophisticated. Rather, Hegel offers a third variety of Neo-Aristotelianism which can account for what seems attractive in the other two varieties that dominate the contemporary Neo-Aristotelian debate. Hegel undermines the debate by calling into question an assumption that neither naive nor sophisticated Aristotelianism even considers questionable. This is the assumption that the Aristotelian distinction between three forms of lifethe vegetative, the animal and the rational form of life-is a distinction that is available to us independently of an understanding of rational life. Hegel denies this assumption. This has decisive consequences for how he conceives Bildung and its relation to the human. The idea of Bildung, Hegel will argue, although it describes an empirical process, is not an empirical concept. Rather, it is the concrete concept of the form of rational activity that reflects the temporality of this form. 


\section{Andrea Kern}

II.

To bring the debate into view, it will be helpful to sketch, on an abstract level, the common ground between our three opponents, which can be characterized by three points that - in the context of our topic — are significant. The first is the following: All three varieties of Aristotelianism share the idea that the distinctiveness of the human should be conceived in terms of a difference in 'form'. They share the idea that the distinction between human and non-human animals is a logical distinction in the form of life that they exhibit. The term for this formal difference is 'rationality'. This thought places all three varieties of Aristotelianism in opposition to most contemporary philosophy. For it denies that the so-called anthropological difference can be captured in terms of certain capacities that a human being possesses and other animals don't. Most contemporary philosophy thinks of the anthropological difference, as Hegel would express it, in terms of different 'predicates of life' instead of a difference in the concept of life (E III: $\$ 377,3 / 9$ ). According to any broadly Aristotelian conception, the anthropological difference concerns the principle on account of which something exhibits the unity of a living being, i.e., the unity of something that figures as a subject of a manifold of predicates of life, predicates that characterize capacities that manifest themselves in a variety of vital operations.

At first glance one may be tempted to think that Aristotle, when he distinguishes the three forms of life-that is vegetative life, animal life and rational life-distinguishes them in terms of the capacities that are operative in them. For example, when he writes about the difference of plants from animals: 'This power of self-nutrition can be separated from the other powers mentioned, but not they from it - in mortal beings at least. The fact is obvious in plants $[\ldots]$ ' (DA: II.3, 414a33-b1). Or when he writes: 'Certain kinds of animals possess in addition the power of locomotion, and still others, i.e. man and possibly another order like man or superior to him, the power of thinking and thought' ( $D A$ : 414b16f.). However, it would be a misunderstanding to assume that Aristotle thinks he could draw the formal distinctions he draws within the concept of life through the idea of particular capacities that are added to a more primitive form of life. Rather, he thinks we must draw distinctions on the level of the form on account of which something is alive.

It is for this reason that Aristotle makes sure, after having introduced some of the capacities that make up the unity of a form of life, that we understand the relation between these capacities in the right way. We must understand them as parts of a unity to which it is impossible to add, as it were, further parts, without thereby transforming the character of the unity to which they belong and thereby transforming the role of each part in it. He writes: '[L]iving beings — constitute a series, each successive term of which potentially contains its predecessor, e.g. [...] the 


\section{Life and Mind}

sensory power [contains] the self-nutritive' (DA: 414b29-32). This means that the step from vegetative life to animal life is not a step in which a further predicate of life is added to life-perception added to nutrition-but a step from a life whose vital principle is the nutritive capacity to a life whose vital principle is the perceptive capacity in which the nutritive capacity is contained. And equally: The step from animal life to rational life is not a step in which a further predicate of life is added to a prior unity of predicates — thinking added to sensation-but a step to another form of life, whose vital principle is the intellectual capacity in which the perceptive capacity and the nutritive capacity are contained.

The second thought that is common ground among our three varieties is that all three think that small children do not yet exhibit any of the activities in terms of which we understand what it means to be a rational being such as thinking and judging, giving and asking for reasons, etc. That is, they share the idea that there are certain characteristic activities in terms of which we understand the idea of rationality that is meant to characterize human life and that judging and responding to reasons are these activities, or at least, that they are among them.

As a consequence, there is a third point of agreement between them. All three varieties think that in order to be able to endorse both claims, that is, (1) that human beings differ formally from any non-human animal in terms of rationality and (2) that small children do not yet exhibit any activity that is characteristic for rationality, one must employ Aristotle's distinction between two senses of the idea of potentiality that he develops in De Anima. In book II, chapter 5 Aristotle introduces this distinction between two meanings of the idea of potentiality, a distinction that he thinks is needed to understand life. The example by which he introduces the distinction is the twofold manner in which one can say of a human being that she is capable of theoretical understanding. Aristotle writes:

But we must now distinguish different senses in which things can be said to be potential or actual; at the moment we are speaking as if each of these phrases had only one sense. We can speak of something as a knower either as when we say that man is a knower, meaning that man falls within the class of beings that know or have knowledge, or as when we are speaking of a man who possesses a knowledge of grammar; each of these has a potentiality, but not in the same way: the one because his kind or matter is such and such, the other because he can reflect when he wants to, if nothing external prevents him. And there is the man who is already reflecting - he is a knower in actuality and in the most proper sense is knowing, e.g. this A. Both the former are potential knowers, who realize their respective potentialities, the one by change of quality, i.e. 


\section{Andrea Kern}

repeated transitions from one state to its opposite under instruction, the other in another way by the transition from the inactive possession of sense or grammar to their active exercise. (DA: II.3, 417a21-b2)

Someone can be said to be capable of theoretical understanding in a sense that does not imply that she has learnt and acquired any particular theoretical knowledge such as knowledge of grammar. The reason why she can be said to be capable of theoretical understanding is not that she has, in fact, some knowledge but that she, being human, belongs to a species that is capable of theoretical understanding. Knowledge is a mere potentiality for her, that is, it is in no sense an actuality. In another sense someone can be said to be capable of theoretical understanding in a sense that does imply that she has learnt and acquired some knowledge. Knowledge of grammar is no longer a mere potentiality in her, but is in some sense actual. This need not mean that she, who is capable of theoretical understanding in this sense, is exercising the capacity she has acquired by studying further aspects of grammar. She may be asleep or watching a movie. So there is still a sense in which her knowledge of grammar is a potentiality, i.e., something that is not actualized.

All three varieties think that the Aristotelian distinction between two meanings of the idea of potentiality is the key to combining the other two claims made above and which they both share. However, as we will see, all three varieties have a different interpretation of this Aristotelian distinction, and hence a different interpretation of the idea of a form of life that goes with it, as well as a different interpretation of the idea that small children do not yet exhibit any of the activities in terms of which we understand the idea of rationality that characterizes the human.

\section{III.}

Our overall question is: how should we understand the idea that rationality is the distinctive form of human life? Sophisticated Aristotelianism offers the following interpretation: To think of rationality as the form of human life is to take the concept of the human to describe a system of vital capacities whose principle of unification is self-consciousness. This self-consciousness that characterizes a human being's rationality is not something that a human individual possesses by nature, as part of its natural endowment, but something that a human being acquires in the course of a process of Bildung through which the human individual, who begins its career as a merely sensible being, becomes a rational animal (McDowell 1996). According to John McDowell, who defends this position, the paradigmatic 


\section{Life and Mind}

capacity that constitutes this self-conscious system of capacities is the capacity to employ concepts in judgments whose content one can understand and for which one can give reasons, ask for reasons and receive reasons. ${ }^{2}$ That is, the idea of a capacity to judge, although it does not exhaust the idea of selfconsciousness, is central to our understanding of the self-conscious character of other capacities. And in this sense, the idea of self-consciousness and the idea of a capacity to judge go together.

According to this position, the Aristotelian distinction between two senses of potentiality should be understood as follows: Human beings, qua rational animals, are the result of a process of Bildung that transforms a sensible animal, which is only potentially in possession of this self-conscious system of capacities that defines rationality, into an animal that is actually in possession of them. Bildung transforms an individual that possesses these capacities that constitute its unity qua selfconscious being merely potentially into an individual who possesses them in actuality.

Two points are crucial for this account: (1) Metaphysically there is no difference between small children and non-human animals. The fundamental principle of their activities is described in terms of capacities that do not yet entail the system of capacities that constitutes rationality. (2) To be a subject of Bildung is to undergo a metaphysical transformation from a non-rational being into a rational being. Thus Bildung is depicted as a process by which a metaphysically different kind of individual comes into existence. 'Responsiveness to reasons', as McDowell writes, 'marks out a fully fledged human individual as no longer a merely biological particular, but a being of a metaphysically new kind' (McDowell 2009: 172). This metaphysically new kind of individual has not only a first nature but also a second nature that is the source of its rational activity. According to this position, the idea of the buman life and the idea of a rational life are distinct in meaning. Although the concept of the human life contains the concept of a rational life, it is not identical with it. For one can be a human being without being a rational animal.

\section{IV.}

The naive Aristotelian thinks that this sophisticated way to invoke the idea of Bildung and second nature, in order to account for a human being's rationality as something that is part of nature, is incoherent. According to the naive Aristotelian, any position that thinks of Bildung as a metaphysical transformation is committed to the idea that the self-conscious system of capacities that it identifies with rationality and the concept of Bildung are only externally related to each other. The naive Aristotelian thinks that the sophisticated Aristotelian is committed to the thought that there could be rational life forms other than the human one, forms that could instantiate a self-conscious system of capacities other than through 


\section{Andrea Kern}

Bildung. In the eyes of the naive Aristotelian, the sophisticated Aristotelian is committed to the thought that it is only a fact about the human species that its individuals have to undergo Bildung in order to instantiate a self-conscious system of capacities, but not something that is intrinsic to the very idea of rationality in terms of which they are analyzed. ${ }^{3}$ The naive Aristotelian thinks that this is wrong. Hegel, as we will see below, shares this criticism. Hegel too thinks that this is a misunderstanding of the role of Bildung. Part of what is wrong with the sophisticated conception is that it does not think of Bildung as an 'immanent moment of the absolute', as Hegel will say (PR: $\$ 187,226 / 345)$.

The naive Aristotelian thinks that there is no level of understanding the concept of the human that can be disentangled from the concept of a rational form of life in terms of which it is analyzed. There is no biological concept of the human. According to this view, the kind which a fully-fledged human being instantiates is metaphysically no different from the kind which small children instantiate. This is not because small children are born with the capacities that, according to sophisticated Aristotelianism, must be acquired in the course of their upbringing. Rather, it is because, according to naive Aristotelianism, the idea of rationality in terms of which we characterize the form of the human life must be understood differently. It must be understood as an aspect of a form that contains, qua form, an explanation of the actuality of this form in the vital activities of its bearers. That is, it must be conceived as a form that is, as such, a form of life. For this is what makes a form not just any old form, but a form of life, according to the naive Aristotelian: a form of life is a form that provides, as such, an explanation of the life activities of its bearers. What holds a form of life and the activities of its bearers together is that a form of life is that which explains their existence and identity. A form of life is thus not only something under which the life activities of its bearers are subsumed, but also something that is actualized in them. This is so whether the form of life is rational or not. However, when the form of life is rational, then we are dealing with a form of life that provides a different kind of explanation for the activities of its bearers from the kind of explanation that animal form provides. We are dealing with a form of life that provides a distinctively rational explanation.

Thus when Aristotle distinguishes three forms of life- the vegetative form of life, the animal form of life, the rational form of life-from one another, what he wants to say, according to this suggestion, is that we can distinguish three different specifications of the abstract idea of explanation that characterizes the relation of a form of life to the vital activities of its bearers. The term 'rationality' designates one such specification. It designates a specific idea of explanation that unites a form of life and the vital activities of its bearers not by determining any particular content of explanation but by determining the principle of the explanation that this form provides. In the case of rational life, according to the naive Aristotelian, the principle of its explanation is self-consciousness. Self-consciousness, according to 


\section{Life and Mind}

this position, is the principle of the explanation that unites a rational form of life and its bearers. That is to say, a rational form is a form of life that explains the activities of its bearers by being represented by them. This is how Michael Thompson describes the idea of a rational form of life:

In representing any animal as thinking or as in pain, I bring it to a certain formally distinctive unity; in representing it as bearing self-knowledge of these things, I represent the animal as bringing itself to a unity of the same type. Self-consciousness is always implicitly form consciousness. [... T] his will have to be a feature of the life form itself: it belongs to the prosecution of such life to see things in the light of it, as we might say. Its representation is a part of it. (Thompson 2013: 727)

A rational form of life, according to the naive Aristotelian, is a form of life that would not explain the life of its bearers, and hence not be a form of life, if its bearers were not conscious of it and did not act in the light of their representation of it. It is a form of life that depends on its subjects' having a representation of it that represents their activities as manifestations of it. The idea of an activity that entails, qua activity, a representation of itself as a manifestation of a form of life, Thompson argues, is the idea of an activity which entails the employment of vital concepts in various forms of self-explanation that articulate the unity that one represents when one acts in the light of one's form of life (Thompson 2008: 198).

Philippa Foot expresses a similar idea when she argues that a rational form of life is one whose bearers do not just have ends for which they act but whose bearers are such as to know 'an end as an end or a means as a means to that end' (Foot 2001: 54). And being able to know an end as an end, she concludes, is only intelligible in the context of the capacity to employ concepts of ends that articulate one's form of life, whose possession one manifests, among other ways, by responding to such questions as why one is doing such and such with forms of explanation that bring to bear one's understanding of one's form of life (Foot 2001: 55).

Thus the naive Aristotelian thinks that the concepts of actualization and manifestation that we employ to characterize the explanatory nexus between a form of life and its individual bearers has a specific meaning when applied to a rational form of life. It takes on a specific meaning because the logical form of its application is specific. When applied to a rational form of life it describes an explanatory relation between a form of life and its individual bearers and their activities, the holding of which depends on the individual's capacity to give this explanation berself. When applied to an instance of a rational form of life the concept of actualization describes an explanatory relation whose form is first-personal. 


\section{Andrea Kern}

If that is so, then the concept of the human as we apply it to ourselves, the naive Aristotelian concludes, cannot be related to the concept of a rational form of life as the concept of an instance to the concept of a genus. It must rather be the material concept of a form of life whose formal concept is the concept of rational life in the above sense. Its material concept differs from its formal concept not in that the latter describes the genus of which the human life describes a species, but in that the concept of the human contains everything that is contained in the concept of a self-conscious form of life in virtue of being employed in various forms of selfpredication. The question of how a human being comes to be rational in the sense of self-conscious is therefore void of meaning. To conceive of an individual as something that instantiates the same vital concept as oneself-that is, the concept of a human being - already entails that one conceives of the individual in question as a subject of vital operations that manifest, as such, self-consciousness.

According to the naive position, the kind that a fully fledged human individual exhibits is therefore, indeed, metaphysically different from the kind that any other non-human individual exhibits. However, the account of this metaphysical difference does not exclude but presupposes that the vital activities of small children, no matter at what stage and age of their career, cannot fail to exhibit it.

\section{V.}

Sophisticated Aristotelianism is motivated by the thought that any position that does not credit Bildung with bringing about a metaphysical transformation from a sensible being into a rational animal is committed to viewing the power of selfconsciousness - which characterizes the formal difference between a merely animal form of life and the human form of life- - has a power that human beings possess 'by nature', just as a mouse possesses the power to breathe. It must be conceived as an inborn capacity, as part of its natural endowment. ${ }^{4}$ What makes sophisticated Aristotelianism attractive is that it rejects this picture. The form that a human being possesses qua rational animal is not something that characterizes its bearers prior to and independent of Bildung. This cannot be so because the form that a human being exhibits qua rational animal is a form, the sophisticated Aristotelian thinks, whose actualization is a matter of freedom and responsiveness to reasons. This must mean, the sophisticated Aristotelian concludes, that the individual in question acts in a manner that is no longer a mere manifestation of her sensible form but a manifestation of reasons that she has acquired through Bildung and in virtue of which she can represent her activity to be good or true. By contrast, what makes naive Aristotelianism attractive is that it is able to provide an account of the very possibility of Bildung in human life which the sophisticated one 


\section{Life and Mind}

cannot but presuppose as a natural fact about human beings without being able to account for it.

\section{VI.}

I now turn to our third variety of Aristotelianism. This is Hegel's position, or so I will argue. Hegelian Aristotelianism thinks that the debate between the above two varieties of Aristotelianism reflects a shared misunderstanding of the relation between rationality and the idea of life, which explains their disagreement. According to Hegel both varieties presuppose that the notion of animal life is intelligible prior to and independently of the notion of life whose form Hegel calls Geist. They both think that the notion of animal life is logically available prior to and independently of an understanding of that form of life whose form consists in a concept that is manifested in an activity that grasps its concept, as Hegel characterizes minded life at the beginning of his 'Anthropology' (E III: \$377, 1/9).

Hegel thinks that this is a misunderstanding. The idea of minded life, Hegel argues, is logically prior to the idea of animal life. None of the concepts that we employ to characterize animal life and its life process, he thinks, can be understood apart from the meaning that these concepts have in an articulation of the idea of minded life. Thus none of the concepts that we employ to characterize animal life and its life process can be employed to characterize the difference between animal life and minded life. By contrast, the debate between our two varieties of Aristotelianism is shaped by the assumption that we can distinguish rational life from non-rational life in terms of notions that are available prior to and independently of an articulation of that form of life that we thereby want to distinguish: such as the distinction between two different principles of acquiring capacities, the one called 'by nature', the other 'by Bildung'. Hegel denies this assumption. This has consequences for his characterization of the relation between minded life and the idea of Bildung as well as for his characterization of the relation between the three forms of life that Aristotle distinguishes. In what follows I focus on the former, that is, on Hegel's characterization of what he calls minded life. The second question will have to be the topic of another paper.

At the beginning of his treatment of the notion of life in his Logic Hegel tells us that the concept of life is the first representation of what he calls 'the idea'. 'The idea', he tells us, is the 'adequate concept', that is, 'the objectively true, or the true as such' (WL: 670/462). It is the 'totality of the concept and the objective' (671/462). Hegel arrives at this insight at the end of the Logic's chapter on Teleology. His thought is that the teleological form of thinking that the concept of life contains, is, as such, a valid form of thinking. To represent something as alive is to represent something through a concept that explains the identity and existence of that which is 


\section{Andrea Kern}

represented through it. This form of thinking, Hegel argues here, is not just a mere form of thinking, that we might recognize to be necessary to represent something as alive, as Kant would have seen it. It rather is a form of thinking that has objective validity, just as Aristotle thought of it. To employ the concept of an inner purposiveness, Hegel takes himself to be able to show, is to employ a form of thinking without which thinking cannot provide for that which it pretends to be, that is, the thinking of something. Thus when Hegel argues that the idea of life is 'the objectively true or the true as such' he wants to correct, among other things, the Kantian misunderstanding according to which the concept of life is a mere principle of reflection that lacks objectivity. Rather, he thinks that he is able to establish the objective validity of the teleological form of thinking that the concept of life entails.

However, Hegel also says of the concept of life that merely represents animal life that, although the form of teleological thinking that it contains is objectively valid, it is not yet the 'true presentation or the true mode of its existence' (WL: 694/494). He writes:

We have seen regarding life that it is the idea, but at the same time it has shown itself not to be as yet the true presentation or the true mode of its existence. For in life, the reality of the idea is singularity; universality or the genus is the inwardness. The truth of life as absolute negative unity consists, therefore, in this: to sublate the abstract or, what is the same, the immediate singularity, and as identical to be self-identical, as genus, to be self-equal. Now this idea is spirit. (WL: 694/494)

Thus Hegel thinks that the form of teleological thinking reached with the concept of animal life represents what is objectively true - that is, life- but that this form does not yet have the true mode of being of the adequate concept. The reason for this is that it does not represent what it represents as objectively true as something whose actuality, as such, is the actuality of the generality of the concept through which it is represented, but rather as something whose actuality is in opposition to the concept's generality. The concept of animal life represents the life that it represents in such a way that the concept as concept is external to the life that it represents. That is, it does not represent the life that it represents as something that contains, as such, an actualization of the generality of the concept through which it is represented. The concept of animal life, according to Hegel, is therefore not self-standing. It lacks intelligibility because the generality of the concept that one employs to represent animal life is not itself part of what is understood through this concept. It is a concept that does not render intelligible its own actuality as concept. 


\section{Life and Mind}

This is why Hegel argues that the concept of animal life is logically dependent upon another concept of life that entails, as such, an actuality of the concept's generality. Hegel concludes that we must think a form of life whose activities, as such, are an actualization of the concept as concept. A form of life whose activities consist in an actualization of its concept as concept, Hegel thinks, is a form of life whose vital activities consist in a grasping of its concept, and hence of itself.

Hegel's notion of Geist, introduced after the Life chapter of his Logic, is the concept of such a life's form. It characterizes a form of life whose concept describes vital activities that consist, as such, in grasping the concept that these activities actualize. According to this suggestion, the concept of Geist, as Hegel employs it here, is related not merely superficially but systematically to the concept of the intellect, nous, as Aristotle employs it within his treatment of the idea of life and his distinction of three different forms of life. ${ }^{5}$ In his Lectures on the History of Philosophy, Hegel makes explicit his indebtedness to Aristotle's conception of life. Hegel praises Aristotle's so-called philosophy of mind, as he expounds it in De Anima, for two insights that he takes to be the most speculative thoughts in Aristotle. The first is Aristotle's insight that the distinctions between the three forms of life that Aristotle is able to draw are not distinctions in terms of predicates of life, but logical distinctions. However, they are logical distinctions within a concept which, as such, is the concept of something real. Hegel takes this to be one of Aristotle's deepest speculative insights. He credits Aristotle with having recognized that the concept of life is 'a universality that is so real that it itself, without further changes, is its first kind' (VGP: 204). In Aristotle, the concepts of vegetative life, animal life and rational life are supposed to be those fundamental determinations of the concept of life in virtue of which it describes something real. This is, as Hegel praises, a 'deep remark that distinguishes the genuinely speculative thought from the merely logical formal thinking' (203). The second insight that Hegel finds in Aristotle is his conception of nous, or what Hegel takes to be his conception. When Aristotle says of nous that it is the 'totality of being', Hegel takes this to mean that nous, and hence the totality of being, is as entelechy, 'als Entelechie' (217). That is to say, nous, and hence the totality of being, must be conceived as the developed actualization of a potentiality. Hegel takes this to mean that nous, according to his reading of Aristotle, is

a thinking of that which is the best, the end in and for itself; this is the nous that thinks itself. [...] The nous thinks itself through the taking in of that which is thinkable; this thinkable comes to be as affecting and thinking, it is brought about by affecting - and only through this is it in thinking, in the activity of thinking. (VGP: 218) 


\section{Andrea Kern}

Hegel leaves no doubt that he thinks that Aristotle, in his conception of nous, has reached the most speculative thought. He has reached the

thought of the thought, the thinking of the thought; unity of subjective and objective is therein articulated, and that is perfection. The absolute end, the nous that thinks itself — and that is the good; this is only with itself, for the sake of itself. This is the highest point of Aristotelian metaphysics, the most speculative there is. (VGP: 219)

The concept of Geist as it appears after the Life chapter in Hegel's Logic is supposed to reflect these two crucial ideas that Hegel praises in Aristotle. According to them, the concept of Geist, or mind, is

1) the concept of a form of life which, as such, describes something real, and in this sense, something determinate and concrete.

2) the concept of a form of life that is manifested in an activity of thinking which, in thinking the totality of the thinkable, thinks itself, that is, its concept.

In what follows I explore Hegel's notion of minded life from an angle particularly relevant to our topic. I will consider the beginning of his treatment of the subjective mind and argue that the concept of the human as it enters there is not the concept of an instance of minded life, but the concept of the concrete and determinate life whose form is Geist. Thus Hegel shares the naive Aristotelian insight that the concept of minded life is not the concept of a genus. Rather, the concept of the human is the concrete concept of the form of minded life. At the same time, however, Hegel denies the naive Aristotelian assumption that the three forms of life that Aristotle distinguishes are logically on the same footing. A form of life that is manifested in an activity of thinking that, qua thinking the totality of the thinkable, thinks itself, according to Hegel, cannot be conceived as a specification of the concept of life alongside other specifications such as vegetative life and animal life. If part of what it is to instantiate such a form of life is to think 'itself through the taking in of that which is thinkable', then this form of life cannot think itself as a particular form of life that contrasts with another, equally particular form of life, let's say vegetative life or animal life. Rather, its thinking of itself through the taking in of that which is thinkable will already entail the vegetative life as well as the animal life as part of what it thinks when it thinks itself and hence it will be thought as something that is, in this sense, not identical with itself but only contained in what it itself is. The concept of a form of life that thinks itself by taking in the thinkable is, as Hegel writes, 'in itself totality, the true as such' (VGP: 219).

It matters for our question - how to conceive of the rational form of life and Hegel's appropriation of the Aristotelian notion of the intellect- that Hegel on the 


\section{Life and Mind}

one hand introduces the notion of Geist as the notion of a distinctive form of life, yet on the other hand denies that this distinctive life is one particular form of life within a manifold of forms of life, such as vegetative life and animal life. Rather, Hegel argues that in the order of understanding, the concept of a form of life whose actualization consists in the thinking of itself is prior to an understanding of other forms of life-the vegetative and the animal. Minded life is the logically fundamental form of life. Not in that one can think minded life without thinking vegetative life and animal life. On the contrary, it is logically prior in that the thinking of vegetative life and animal life is not the thinking of something other than minded life, but the thinking of limited forms of life that are contained in the concept of minded life. The concept of minded life is a concept that is not limited by other vital concepts that it excludes from itself, but rather contains these other concepts in itself.

\section{VII.}

Central to the debate between the sophisticated and the naive Aristotelian is how to understand the idea of potentiality that we need in order to combine the ideas that a human being has a form of life logically distinct from the form of life of any nonhuman animal, on account of its rationality, and that small children do not yet exhibit any of the activities characteristic of rationality, such as judging, speaking a language, etc. It is common ground among all varieties of Neo-Aristotelianism that the distinction between two senses of potentiality that Aristotle applies to the living as such is the key to combining both ideas. However, how to use this key, as it were, is conceived differently in each position. As we will now see, Hegel employs the Aristotelian distinction between two senses of potentiality in a different way from both the naive and sophisticated positions. This is a consequence of his view that the concept of minded life is not the concept of a particular form of life but the concept of the logically fundamental form of life.

Hegel explicitly addresses the above question in his treatment of subjective mind, which begins with what he calls the mind's 'Anthropology'. As I argued above, Hegel shares with the naive Aristotelian the thought that the generality of minded life is not the generality of a genus that could have several species with human life as one of them. It is not the generality of a predicate that could be applied to a manifold of things or employed as a predicate in judgments that have different subjects. This is so, Hegel will argue, because its generality is nothing other than the generality of the activity of thinking in which a subject represents her activity as the actualization of the concept of life that she predicates of herself in this thought. The content of the concept of the human, according to Hegel, is 


\section{Andrea Kern}

the concrete unity of these acts of self-predication. This is why the study of the subjective mind begins with the mind's 'Anthropology'.

In $\$ 396$ of the 'Anthropology' Hegel tells us-from the standpoint of the concrete unity that the concept of the human describes, as he assures us several times - what it is to represent an individual that manifests a minded form of life as a unity of natural determinations that Hegel, in $\$ 395$, identifies as dispositions like temperament, talent, character and physiognomy. To represent an individual of a minded form of life as a unity of natural determinations (such as character, talent, etc.), Hegel argues, is to represent it as the unity of a process of development that has a logically unique form. For it means to represent it as the unity of a process of development that consists, in each of its moments, in an activity of dissolving the contradiction between the two logical determinations that characterize life. The contradiction that characterizes life, as we saw above, is the 'contradiction between the immediate individuality and the substantial universality implicitly present in it' (E III: \$396Z, 55/75). This is Hegel's abbreviated formulation for the above thought that to represent something as alive is to represent the subject of the thought as something singular ('the immediate individuality') by subsuming it under something general (the 'substantial universality') that inheres in it as that which explains its existence and identity. The process of life, Hegel argues, is the process of overcoming the contradiction between these two logical determinations of life, a process which characterizes not only human life but merely animal life as well. As Hegel writes: 'Even merely animal life in its way exhibits this process implicitly' (E III: \396Z, 55-56/76).

What makes human life, qua minded life, unique is that its life activity consists, as such, in the dissolution of this contradiction that animal life is incapable of overcoming. This is so because minded life, as we have seen, is 'the actualized concept that is for itself' $(\$ 382 Z, 15 / 26)$. A life that is 'the actualized concept that is for itself' is a life whose form entails, qua form, a consciousness of itself in the life of those who manifest this form. Minded life is a life whose form, in this sense, is self-conscious form. A life in which the nexus between its form and the individual activities that manifest this form is self-conscious dissolves life's contradiction. For to think a self-conscious form of life, Hegel argues, is to think a life whose form is self-determining. It is to think a life whose vital activity consists, in each of its stages, in an activity of determining its form by determining itself through it. For a life whose form is self-determining in this sense is a life in which the general form, which inheres in the individual's activity as that which explains its existence and identity, is no longer external to the activity that actualizes this form because both are determined through each other.

Hegel's argument is thus: To think a self-conscious form of life is to think a life whose unity is identical with the thinking of it. A life whose unity is identical with the thinking of it is a life whose form is self-determining. But what does it 


\section{Life and Mind}

mean to think a life whose form is self-determining? \$396 of the 'Anthropology' tells us in nuce what it means to think the unity of an individual whose life has a self-determining form. It means to think a unity of natural qualities (such as character, temperament und talent) which is the subject of a distinctive form of development that Hegel calls Bildung. For Bildung, Hegel argues, is the process in which

the initial, simple unity of the soul with itself is raised to a unity mediated by the opposition, and the initially abstract universality of the soul is developed to concrete universality. This process of development is Bildung. (E III: \$396Z, 55/76)

Thus the notion of Bildung as Hegel employs it here characterizes, not a particular vital activity of a human being that sets in at a particular moment in its life-time, but the distinctive form of development that makes up the unity of an individual that exhibits a minded form of life. To be a subject of Bildung is not one of many things that a minded individual comes to be a subject of, as it becomes a subject of swimming or speaking a language, or running and dancing, or drinking and laughing. The notion of Bildung rather specifies what it means to be a unity of any determination whatever that manifests a self-determining form. It means to be the subject of a form of development whose concrete description looks as follows:

It begins with the child, the mind wrapped up in itself. The next step is the developed opposition, the tension between a universality which is still subjective (ideals, imaginings, moral demands, hopes, etc.) and immediate individuality, i.e. both the existing world, which fails to meet the ideals, and the position in it of the individual himself, who, in his current state, still lacks independence and intrinsic maturity (youth). Next there is the genuine relationship: recognition of the objective necessity and rationality of the world as we find it, a world no longer incomplete, but able, in the work which it accomplishes in and for itself, to afford the individual a share and a confirmation for his activity. This makes the individual somebody, with actual presence and objective value (man). Last of all comes the completion of the unity with this objectivity: a unity which, while in its reality it passes into the inertia of deadening habit, in its ideality gains freedom from the limited interests and entanglements of the external present (old age). (E III: \$396, 55/75).

Minded life, Hegel wants to say, is a distinctive form of life because to actualize it is to be the subject of a development that consists, in each of its moments, in an activity of overcoming the contradiction between the immediate (and, that is, abstract and indeterminate) individuality that one is and the universality of the form that 


\section{Andrea Kern}

explains one's existence and identity and which, at the beginning of an individual's life, is equally only abstractly and indeterminately present in one's life. Therefore Hegel says that only human life has the 'power genuinely to actualize the genus within itself', that is, to dissolve the contradiction of life (E III: $₫ 396 Z, 56 / 76$ ). Only in human life does the generality of the form become concrete generality, just as the individuality of the individual becomes concrete individuality because only human life is a self-determining form. The mere animal, by contrast, 'does not have the power genuinely to actualize the genus within itself; its immediate, abstract individuality, an individuality that simply is, always remains in contradiction with its genus, both excluding it from itself and including it within itself' ( $\$ 396 \mathrm{Z}$, 56/76).

It might be helpful to notice that, when Hegel denies that the mere animal, such as my cat Charlie, is a concrete individual, he does not want to deny that she, in standing in a relation to me, has quite remarkable and distinctive character traits that distinguish her from my other cat Leo who has other character traits. What Hegel wants to say is that we may not confuse these character traits of my cats with the role that the idea of a character plays in human life. In a cat's life it is an aspect of her individuality by which we can distinguish one cat from another. But this distinguishing characteristic is not itself part of the concept of the form of life that we bring to bear when we individuate something as a cat. This is different in human life. In human life, an individual's having a character is an aspect of her individuality that cannot be disentangled from the unity she has qua subject of Bildung. Her character is something that she has qua subject of Bildung-and that means qua being engaged in a process of determining herself through a form of life whose content she thereby determines. That is, by being engaged in a process of becoming a concrete I that is able to represent herself as a genuine manifestation of her form of life. And this is not the meaning that the idea of a character has when applied to my cats. ${ }^{6}$

\section{VIII.}

We can now see more clearly that and why the concept of Bildung, as Hegel employs it in his 'Anthropology', does not describe a particular activity of human individuals distinguishable from other activities of human individuals; nor does it describe a particular activity that begins at a certain moment in their lives and ends at a certain moment in their lives. It rather specifies the distinctive form of development that characterizes the unity of a subject whose activities exhibit a self-determining form.

Hegel's account of Bildung has decisive consequences for our understanding of those individuals who are its subject. Everybody agrees that a newborn baby does not yet have concepts. For Hegel, this idea is wrongly spelled out in terms 


\section{Life and Mind}

of individuals that have intuitions with non-conceptual content. Rather, they do not yet have intuitions at all, but only sensations. However, these sensations, Hegel argues, when thought of a human being instead of a mere animal, have on account of its concept to be characterized in one of two ways. This is either as sensations of an already developed concrete I-as sensations of an individual whose unity consists in something other than mere sensations because its sensations are integrated into a conceptually articulated unity of determinations that make up the concrete I. Or they are conceived as sensations of an individual whose unity is about to become a concrete I by acquiring what Hegel describes as consciousness, self-consciousness, and reason as the different logical stages of the development of her capacity to genuinely actualize her form, that is, to manifest a form of life that is conscious of itself (E III: \439, 165/229).

In application to a human being the concept of sensations therefore has a formally distinctive meaning. Sensations, in a human individual, are not determinations of an individual that is incapable of overcoming the abstractness of the concept of life applied to it. They are determinations either of an already developed concrete I or of a coming to be one. Thus, there is an important similarity between a human being and a mere animal in that both have sensations - which Hegel characterizes as the differentia specifica of the mere animal and which means, in the language of the Encyclopaedia, that there is a 'self for the self' (E II: \351Z, 432). Yet this self-feeling that defines animality is not the same in a mere animal as in a child about to become a concrete I. One of the main insights of Hegel's account of minded life is to enable us to see why and in what sense the concept of sensation, in application to a child, has a different meaning from the one it has in application to a mere animal. The reason is that in the life of an individual whose form of life is the mind, its being determined by sensations is a moment of a unity which consists, qua unity, in the becoming of a concrete I. And this is not what it means for a mere animal to be determined by sensations.

\section{IX.}

Hegel's account of rational life, I argued at the beginning, is a distinctive variety of Aristotelianism. Hegelian Aristotelianism states that the actualization of a form of life whose form is the mind has a distinct character because its vital activity consists in an activity of self-determination. I have argued that the concept of Bildung is the concept of the concrete form that this activity takes, which reflects in its very concept the inner temporality of this activity. On this reading, the notion of Bildung cannot be said to be an activity that has a beginning in the life of an individual. It is not a temporally limited activity, if by this we mean that it begins at a certain moment in the life of an individual whose vital activity is not yet conceived as a 


\section{Andrea Kern}

moment of this activity. Rather, the concept of Bildung reflects the inner temporality that characterizes the actualization of a self-determining form which, as such, has no temporal limitation in itself. It thus characterizes the inner temporality of a form through which, as Hegel says in $\$ 187$ of his Philosophy of Right'the form of universality comes into existence for itself in thought, the only form which is a worthy element for the existence of the Idea' (PR: $₫ 187 R, 225 / 345) .{ }^{7}$ It is for this reason that Hegel comes to conclude that Bildung is the 'absolute transition to the infinitely subjective substantiality of ethical life' and praises himself at the end of $\$ 187$ for having reached the standpoint that proves 'that Bildung is an immanent moment of the absolute, and that it has infinite value' (PR: \$187R, 226/346).

This enables us to answer, from a Hegelian perspective, our original question about how to combine the two claims made at the beginning: the claim that human life, qua rational life, is formally different from non-human life with the claim that small children do not yet exhibit any of the activities characteristic of rational life. Hegel's understanding of rational life allows him to combine both claims in a manner that represents mindedness - with its various stages from feeling to consciousness, to self-consciousness and reason-neither as a result of Bildung nor as an inborn capacity. The mind, on Hegel's view, is neither a capacity that a human being possesses by nature, nor a capacity that results from Bildung. Both characterizations make no sense because both presuppose that we can specify the meaning of the concepts that we apply to a human individual, to explain its determinations, prior to and independently of a specification of the idea of rational life. This Hegel denies. In the case of a rational form of life, according to Hegelian Aristotelianism, to characterize an individual through determinations it has by nature, such as a character or a physiognomy, is not to explain an individual's determinations by something that contrasts with its explanation by Bildung. Rather, it is to explain an individual's determinations in a manner that abstracts from an explanation of the unity that the individual comes to be qua exhibiting a self-determining form of life. Thus the notion of nature, according to Hegel, as it is employed with respect to an individual of a minded form of life to explain its determinations, does not contrast with another explanation on the same logical level. It rather is an abstract explanation of an individual whose concrete explanation is Bildung. It follows that a subject that is engaged in an activity of Bildung cannot be conceived thereby to acquire further predicates of life that are added to those she already has by nature, or to be engaged in an activity that transforms these determinations in one way or another. It rather means that she is engaged in an activity that is the concrete explanation of the concrete unity that she is about to become through it, and that is abstractly explained by the notion of nature. It means that she is engaged in an activity of determining the content of the unity that explains her existence and identity by determining herself through it. When things go well with her, she will thereby become able to articulate the unity whose content she has 


\section{Life and Mind}

determined herself to be in the course of Bildung in a manifold of acts of selfpredication-acts of self-predication whose unity she herself is and which she, on account of that, will never think of herself as a predicate.

\section{Andrea Kern akern@uni-leipzig.de}

\section{Notes}

1 Abbreviations used:

$D A=$ Aristotle, De Anima, in The Complete Works of Aristotle, ed. J. Barnes (Princeton: Princeton University Press, 1984).

E II = G. W. F. Hegel, Enzyklopädie der philosophischen Wissenschaften II, Werke vol. 9 (Frankfurt: Suhrkamp, 1986). Translations are the author's own.

E III = G. W. F. Hegel, Encyclopedia of the Philosophical Sciences III, trans. W. Wallace and A. Miller (Oxford: Clarendon Press, 2007)/Ensyklopädie der philosophischen Wissenschaften III, Werke vol. 10 (Frankfurt: Suhrkamp, 1986). Translations occasionally modified without special notice.

$P R=$ G. W. F. Hegel, Elements of the Philosophy of Right, ed. A.W. Wood, trans. H. B. Nisbeth (Cambridge: Cambridge University Press, 1991)/Grundlinien der Philosophie des Rechts, Werke vol. 7 (Frankfurt: Suhrkamp, 1986).

$V G P=$ G. W. F. Hegel, Vorlesungen über die Geschichte der Philosophie II, Werke vol. 19 (Frankfurt: Suhrkamp, 1986). Translations are the author's own.

$W L=$ G. W. F. Hegel, Science of Logic, trans. G. di Giovanni (New York: Cambridge University Press, 2010)/Wissenschaft der Logik II, Werke vol. 6 (Frankfurt: Suhrkamp, 1986).

2 I have discussed McDowell's position in more detail, with respect to its implicit notion of education and its relation to Kant's notion of self-consciousness, in Kern (2017).

${ }^{3}$ For a position which explicitly endorses this view, see Kenny (1989: 20f).

${ }^{4}$ See, for an objection along these lines, Haase (2017).

${ }^{5}$ Hegel's deep indebtedness to Aristotle has recently been emphasized by Pippin (2018).

${ }^{6}$ I am grateful to Robert Stern who has raised a worry along these lines to which the above paragraph responds.

${ }^{7}$ Birgit Sandkaulen (2014) criticizes Hegel for having reduced the process of Bildung to a 'movement towards generality' and thereby having endorsed a merely affirmative notion of Bildung that is uncritical of existing forms of generality. Andreja Novakovic, by contrast, has suggested that Hegel's notion of Bildung is not only affirmative but also critical. She thinks it crucial to Hegel's notion of Bildung that he identifies it with the 'attainment of a universal point of view', by which 


\section{Andrea Kern}

she means the capacity to look upon one's cultural practices from a standpoint 'from the outside'. See Novakovic $(2017: 86,102)$. My interpretation is critical of both readings of Hegel, because it describes Bildung as the concrete form that the actualization of a self-determining form of life takes, hence as the concrete form of the actuality of a generality that, as such, has no existence prior to this form of actualization.

\section{Bibliography}

Foot, P. (2001), Natural Goodness. Oxford: Oxford University Press.

Haase, M. (2017), 'Geist und Gewohnheit: Hegels Begriff der anthropologischen Differenz', in A. Kern and C. Kietzmann (eds.), Selbstbewusstes Leben. Texte zu einer transformativen Theorie menschlicher Subjektivität. Berlin: Suhrkamp.

Kenny, A. (1989), The Metaphysics of Mind. Oxford: Oxford University Press.

Kern, A. (2017), 'Kant über selbstbewusste Sinnlichkeit und die Idee menschlicher Entwicklung', in A. Kern and C. Kietzmann (eds.), Selbstbewnsstes Leben. Texte ₹u einer transformativen Theorie menschlicher Subjektivität. Berlin: Suhrkamp.

McDowell, J. (1996), Mind and World. Cambridge MA: Harvard University Press.

McDowell, J. (2009), 'Towards a Reading of Hegel on Action', in Having the World in Vien. Cambridge MA: Harvard University Press.

Novakovic, A. (2017), Hegel on Second Nature in Ethical Life. Cambridge: Cambridge University Press.

Pippin, R. (2018), Hegel's Realm of Shadows. Chicago: University of Chicago Press. Sandkaulen, B. (2014), 'Bildung bei Hegel—Entfremdung oder Versöhnung?', Hegel-Jahrbuch 2014: 430-38.

Thompson, M. (2008), Life and Action: Elementary Structures of Practice and Practical Thought. Cambridge MA: Harvard University Press.

Thompson, M. (2013), 'Forms of Nature: "First", "Second", "Living", "Rational" and "Phronetic", in G. Hindrichs and A. Honneth (eds.), Freiheit: Stuttgarter Hegel Kongress 2011. Frankfurt: Klostermann. 